Alba Muñoz Santa

Alba Bellés Bellés

Eric López González

Iván Prats Sánchez

Saray Mormeneo Bayo

Albert Bernet Sánchez

Jesús Aramburu Arnuelos

Maria Font Font

Lucía Fraile García

Mercè Garcia González

\section{Report of sexually transmitted infections prevalence in asymptomatic pregnant women under 25 years old in Lleida, Spain}

Sección Microbiologia Hospital Universitari Arnau de Vilanova, Lleida, Spain

Article history

Received: 12 July 2021; Revision Requested: 21 August 2021; Revision Received: 18 September 2021; Accepted: 21 September 2021; Published: 10 December 2021

\section{Sir,}

Chlamydia trachomatis (CT), Neisseria gonorrhoeae (NG), Trichomonas vaginalis (TV), and Mycoplasma genitalium (MG) are responsible for sexually transmitted infections (STIs) and have an important impact on reproductive health worldwide [1]. STls affect mainly women causing cervicitis and cervical discharge, although in most cases are asymptomatic [2]. Most complications of STls are associated to non-treated asymptomatic pregnant women in which adverse pregnancy outcomes such as premature rupture of membranes, chorioamnionitis, prematurity or low birth weight (LBW) have been reported. Limited data on the role of MG during pregnancy has been published, though a recent meta-analysis revealed it may result in spontaneous abortion and preterm birth, independently of co-infection with other STI [3,4].

Since most STls are asymptomatic, syndrome-based algorithms should not be used, but routine STIs screening tests must be implemented to improve obstetrical outcomes. The current recommendation of the Center for Disease Control and Prevention is to test all pregnant women during the first trimester, with retesting during the third one of women less than 25, and those selected according to risk criteria [5]. However, only in 7 out of 25 states of the European Union, STIs screening is part of prenatal control programs [6]. In Catalonia, it is included on the first trimester prenatal control but only offered to asymptomatic pregnant women under 25 years old or parturients with high risk of infection [7]. The objective of this study is to contribute to the report of $\mathrm{CT}, \mathrm{NG}, \mathrm{TV}$ and $\mathrm{MG}$ prevalence from the STIs screening program offered at our sanitary area to pregnant women under 25 years old.

A total of 537 endocervical swabs and 62 vaginal swabs specimens collected from 599 asymptomatic pregnant women

Correspondence:

Alba Muñoz Santa

Sección de Microbiologia y Parasitologia, Hospital Universitari Arnau de Vilanova

Institut Català de la Salut, Avd Rovira Roure 80, 25198 Lleida, Spain

E-mail: amsanta.lleida.ics@gencat.cat under 25 years old were screened for STIs from January 2019 to October 2020 at the Microbiology Department of the Hospital Universitari Arnau de Vilanova of Lleida, Catalonia, Spain. DNA of the specimens was extracted using EZ1 or OIASymphony equipment (QIAGEN ${ }^{\circledR}$, Hilden, Germany) and real-time multiplex PCR screening for $\mathrm{CT}, \mathrm{NG}, \mathrm{TV}$ and $\mathrm{MG}$ was performed using the Allplex ${ }^{\mathrm{TM}}$ STI-7 kit (Seegene ${ }^{\circledR}$, Seoul, Korea). The reaction was run on the CFX96 real time thermocycler (Bio-Rad ${ }^{\circledR}$, Hercules, California). Total STI prevalence was calculated as the number of positive specimens for all specimens analyzed, while $\mathrm{CT}, \mathrm{NG}, \mathrm{TV}$ and $\mathrm{MG}$ prevalence were done over the total number of positive STI microorganisms, including co-infections.

Total STIs prevalence was of 10.7\% (64/599). The prevalence of $\mathrm{CT}, \mathrm{MG}, \mathrm{TV}$ and $\mathrm{NG}$ is shown together with their percentage of coinfection in Table 1. The 4 targets in study were presented majority in single infection. The percentage of co-infections represents $12.5 \%$ of the total positive samples (8/64). Medical records of MG positive pregnant women were retrospectively reviewed to evaluate their pregnancy outcome. Three pregnant women out of 17 ended up in preterm premature rupture of membranes with no other apparent cause.

The objective of the prenatal STI screening is to detect asymptomatic pregnant women during the first trimester of pregnancy. This is the second report from Catalonia on STIs prevalence in asymptomatic pregnant women under 25 years old. In general, STls prevalence data in pregnant women is still scarce in Spain: Piñeiro et al. reported that CT prevalence was of 6.4\% in Gipuzkoa (2011-2014) [8] and in Catalonia, López-Corbeto et al. showed $\mathrm{CT}, \mathrm{NG}$, and MG prevalence of $9.8,3.7$, and $2.5 \%$, respectively [6]. STIs prevalence of our study are similar to those found in general youth population under 25 years old studied in Catalonia [9], where CT, NG and MG prevalence was of $8.5 \%, 0.6 \%$ and $3.5 \%$, respectively. This study was conducted in sexual and reproductive health centres throughout Catalonia, so it shows higher STIs prevalence. Moreover, a second study done in asymptomatic young sexually active patients attending the emergency room of our 


\begin{tabular}{|c|c|c|c|c|c|}
\hline Table 1 & \multicolumn{5}{|c|}{$\begin{array}{l}\text { Chlamydia trachomatis (CT), Mycoplasma genitalium } \\
\text { (MG), Trichomonas vaginalis (TV), and Neisseria } \\
\text { gonorrhoeae (NG) prevalence. Total number and } \\
\text { percentage of coinfection of each bacterial STI and } \\
\text { percentage of coinfection with other bacterial STI. }\end{array}$} \\
\hline \multirow{2}{*}{\multicolumn{2}{|c|}{ Total No. positive bacterial STI= 74}} & CT & MG & TV & NG \\
\hline & & $N(\%)$ & $N(\%)$ & $N(\%)$ & $N(\%)$ \\
\hline \multicolumn{2}{|l|}{ STI prevalence } & $43(6.2)$ & $17(2.5)$ & $10(1.4)$ & $4(0.6)$ \\
\hline \multicolumn{2}{|c|}{ N (\%) Total Coinfection } & $6(14)$ & $4(23.5)$ & $5(50)$ & $3(75)$ \\
\hline \multicolumn{6}{|c|}{ (\%) Coinfection with other bacterial STI } \\
\hline \multicolumn{2}{|l|}{ CT } & - & 17.6 & 25 & 66.7 \\
\hline \multicolumn{2}{|l|}{ MG } & 5.2 & - & 8.3 & - \\
\hline \multicolumn{2}{|l|}{ TV } & 5.2 & 5.9 & - & 33.3 \\
\hline \multicolumn{2}{|l|}{ NG } & 3.5 & - & 16.7 & - \\
\hline
\end{tabular}

hospital for reasons unrelated to an STI showed a CT prevalence of 7.4\% [10].

Regarding co-infections, our data suggest a moderate level of samples (12.5\%) with more than one STI detected. CT was more frequent in single infection (86\%) while NG was mainly in co-infection (75\%). This data is of interest as it demonstrates that co-infecting microorganisms should be tested so that they can have a significant impact on pregnancy and neonatal complications [6].

In Catalonia, according to the screening program only positive cases of CT, TV and NG are notified. Due to the moderate prevalence of $\mathrm{MG}$, more prospective studies evaluating whether screening programs improve reproductive outcomes in women are necessary to guide public health policies for this emerging pathogen $[3,4]$.

In conclusion, this study supports the need to screen STIs in asymptomatic pregnant women as part of prenatal care in Spain. Furthermore, we consider that there is a need of more extensive STIs prevalence studies, especially in parturients aged above 25 years old to support that the screening protocol could be broadened.

\section{ACKNOWLEDGMENTS}

The authors thank the laboratory technicians for their work on the preparation of the STI PCRs.

\section{FUNDING}

None to declare

\section{CONFLICT OF INTEREST}

The authors declare no conflicts of interest.

\section{REFERENCES}

1. López-Corbeto E, González V, Lugo R, Rivaya B, Casabona J, Matas L; CT/NG Study Group; Investigators of the CT/NG Study Group:. Pooling of urine samples for molecular detection of Chlamydia trachomatis, Neisseria gonorrhoeae and Mycoplasma genitalium as a screening strategy among young adults in Catalonia. Enferm Infecc Microbiol Clin. 2020 Feb;38(2):65-71. English, Spanish. doi: 10.1016/j.eimc.2019.05.003

2. Ortiz-de la Tabla V, Gutiérrez F. Cervicitis: Etiology, diagnosis and treatment. Enferm Infecc Microbiol Clin. 2019;37(10):661-667. doi: 10.1016/j.eimc.2018.12.004.

3. Lis R, Rowhani-Rahbar A, Manhart LE. Mycoplasma genitalium infection and female reproductive tract disease: a meta-analysis. Clin Infect Dis. 2015;61(3):418-26. doi: 10.1093/cid/civ312.

4. Donders GGG, Ruban K, Bellen G, Petricevic L. Mycoplasma/ Ureaplasma infection in pregnancy: to screen or not to screen. J Perinat Med. 2017;45(5):505-515. doi: 10.1515/jpm-2016-0111.

5. Peuchant O, Le Roy C, Desveaux C, Paris A, Asselineau J, Maldonado C, Chêne G, Horovitz J, Dallay D, de Barbeyrac B, Bébéar C. Screening for Chlamydia trachomatis, Neisseria gonorrhoeae, and Mycoplasma genitalium should it be integrated into routine pregnancy care in French young pregnant women? Diagn Microbiol Infect Dis. 2015;82(1):14-9. doi: 10.1016/j.diagmicrobio.2015.01.014

6. López-Corbeto E, González V, Casabona J; Grupo de estudio CT NG. First data of Chlamydia trachomatis and other STI prevalence and co-infections in pregnant women under 25 years in Catalonia, Spain. Med Clin (Barc). 2021;156(1):33-34. doi: 10.1016/j.medcli.2019.12.019.

7. Protocol de seguiment de l'embaràs a Catalunya. 3a ed. rev. Departament de Salut 1. Generalitat de Catalunya. Available from: https://scientiasalut.gencat.cat/handle/11351/1204

8. Piñeiro L, Lekuona A, Cilla G, Lasa I, Martinez-Gallardo LP, Korta J, Pérez-Trallero E. Prevalence of Chlamydia trachomatis infection in parturient women in Gipuzkoa, Northern Spain. Springerplus. 
2016;5:566. doi: 10.1186/s40064-016-2268-4.

9. López-Corbeto E, González V, Bascunyana E, Humet V, Casabona J; Grupo de estudio CT/NG-ASSIR y CT/NG-Prisiones. Tendencia y determinantes de la infección genital por Chlamydia trachomatis en menores de 25 años. Cataluña 2007-2014. Enferm Infecc Microbiol Clin. 2016;34(8):499-504. doi: 10.1016/j.eimc.2015.11.002.

10. Yuguero 0, Fernández-Armenteros JM, Vilela Á, Aramburu J, Laín R, Godoy P. Preliminary Results of a Screening Programme for Chlamydia in an Asymptomatic Young Population in Spain. Front Public Health. 2021;9:615110. doi: 10.3389/fpubh.2021.615110. 